Published in final edited form as:

Biochemistry. 2018 November 27; 57(47): 6604-6614. doi:10.1021/acs.biochem.8b00914.

\title{
Biochemical Characterization and Structure-Based Mutational Analysis Provide Insight into the Binding and Mechanism of Action of Novel Aspartate Aminotransferase Inhibitors
}

\author{
Melissa C. Holt ${ }^{\dagger}$, Zahra Assar $^{\dagger}$, Reza Beheshti Zavareh ${ }^{\ddagger}$, Lin Lin $§$, Justin Anglin ${ }^{\ddagger}$, Oksana \\ Mashadova", Daniel Haldar ${ }^{\perp}$, Edouard Mullarky", Daniel M. Kremer§, Lewis C. Cantley", \\ Alec C. Kimmelman\#, Adam J. Stein ${ }^{\dagger}$, Luke L. Lairson $\ddagger$,@, and Costas A. Lyssiotis ${ }^{\star}, \nabla$ \\ ${ }^{\dagger}$ Cayman Chemical Company, 1180 East Ellsworth, Ann Arbor, Michigan 48108, United States \\ ¥California Institute for Biomedical Research, 11119 North Torrey Pines Road, La Jolla, California \\ 92037, United States \\ §Department of Molecular and Integrative Physiology, University of Michigan Medical School, Ann \\ Arbor, Michigan 48109, United States \\ "Meyer Cancer Center, Department of Medicine, Weill Cornell Medical College, New York, New \\ York 10065, United States \\ ${ }^{\perp}$ Department of Systems Biology, Harvard Medical School, Boston, Massachusetts 02215, United \\ States \\ \#Department of Radiation Oncology, Perlmutter Cancer Center, NYU Langone Medical Center, \\ New York, New York 10016, United States \\ @Department of Chemistry, The Scripps Research Institute, 10550 North Torrey Pines Road, La \\ Jolla, California 92037, United States
}

\footnotetext{
*Corresponding Author: Department of Molecular and Integrative Physiology, University of Michigan, Ann Arbor, MI 48109. clyssiot@med.umich.edu. Telephone: +1-734-615-9133.

Author Contributions

M.C.H., Z.A., and R.B.Z. are co-first authors. A.J.S., L.L.L., and C.A.L. are co-senior authors. R.B.Z. carried out the screening campaign and worked with J.A. to develop the lead compounds. D.H., E.M., and D.M.K. developed reagents for the screening assays. L.L., O.M., and C.A.L. performed the cell-based and metabolomics assays. M.C.H. and Z.A. performed the in vitro assays and computational and X-ray crystallo-graphic studies. L.C.C., A.C.K., A.J.S., L.L.L., and C.A.L. conceived of the project. M.C.H., Z.A., A.J.S., and C.A.L. wrote the manuscript. All authors contributed to the editing of the manuscript. A.J.S., L.L.L., and C.A.L. managed the project.

Supporting Information

The Supporting Information is available free of charge on the ACS Publications website at DOI: 10.1021/acs.biochem.8b00914. Ten supplementary figures that contain additional details about the development and optimization of the GOT1 high-throughput screen, cell-based assays, GOT1 protein production, crystallization, and X-ray structure analysis (PDF)

Notes

The authors declare the following competing financial interest(s): C.A.L. and A.C.K. are inventors on patents pertaining to Krasregulated metabolic pathways, redox control pathways in pancreatic cancer, and targeting GOT1 as a therapeutic approach. A.C.K. also holds a patent on the autophagic control of iron metabolism and is on the SAB and has ownership interests in Cornerstone Pharmaceuticals and Vescor Therapeutics. L.C.C. owns equity in, receives compensation from, and serves on the Scientific Advisory Boards of Agios Pharmaceuticals and Petra Pharmaceuticals. L.C.C.'s laboratory also receives financial support from Petra Pharmaceuticals. Agios Pharmaceuticals is identifying metabolic pathways of cancer cells and developing drugs to inhibit such enzymes to disrupt tumor cell growth and survival.
} 
${ }^{\nabla}$ Department of Molecular and Integrative Physiology, Department of Internal Medicine, Division of Gastroenterology, and Rogel Cancer Center, University of Michigan, Ann Arbor, Michigan 48109, United States

\section{Abstract}

Pancreatic cancer cells are characterized by deregulated metabolic programs that facilitate growth and resistance to oxidative stress. Among these programs, pancreatic cancers preferentially utilize a metabolic pathway through the enzyme aspartate aminotransferase 1 [also known as glutamate oxaloacetate transaminase 1 (GOT1)] to support cellular redox homeostasis. As such, small molecule inhibitors that target GOT1 could serve as starting points for the development of new therapies for pancreatic cancer. We ran a high-throughput screen for inhibitors of GOT1 and identified a small molecule, iGOT1-01, with in vitro GOT1 inhibitor activity. Application in pancreatic cancer cells revealed metabolic and growth inhibitory activity reflecting a promiscuous inhibitory profile. We then performed an in silico docking analysis to study inhibitor-GOT1 interactions with iGOT1-01 analogues that possess improved solubility and potency properties. These results suggested that the GOT1 inhibitor competed for binding to the pyridoxal 5phosphate (PLP) cofactor site of GOT1. To analyze how the GOT1 inhibitor bound to GOT1, a series of GOT1 mutant enzymes that abolished PLP binding were generated. Application of the mutants in X-ray crystallography and thermal shift assays again suggested but were unable to formally conclude that the GOT1 inhibitor bound to the PLP site. Mutational studies revealed the relationship between PLP binding and the thermal stability of GOT1 while highlighting the essential nature of several residues for GOT1 catalytic activity. Insight into the mode of action of GOT1 inhibitors may provide leads to the development of drugs that target redox balance in pancreatic cancer.

\section{Graphical Abstract}

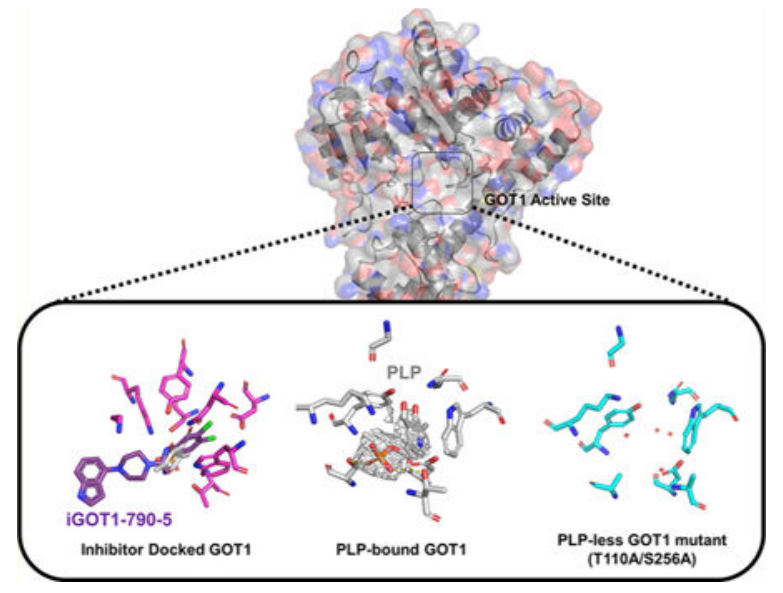

Pancreatic ductal adenocarcinoma (PDA) is projected to become the second most deadly cancer in the United States by 2020, contrasting a relatively low incidence rate. ${ }^{1}$ Metastatic PDA is highly resistant to genotoxic chemotherapy, and even the most aggressive regimens provide only a few months of additional survival. ${ }^{2}$ Like most cancers, metabolic processes in PDA cells are altered to facilitate macromolecular biosynthesis and protect against intra- and 
extracellular stressors. ${ }^{3}$ Reactive oxygen species (ROS) are a byproduct of metabolism and represent a notable metabolic stress to PDA cells. Previously, we described a new metabolic pathway in PDA cells that is used to manage ROS through the maintenance of glutathione (GSH) pools. ${ }^{4}$ Inhibition of an essential enzyme in this pathway, cytosolic glutamate oxaloacetate transaminase 1 (GOT1, UniProtKB entry P17174), is profoundly growth inhibitory in PDA cells and tumors but well tolerated by normal pancreatic cells and fibroblasts. GOT1 metabolic pathways have also been shown to play a role in other cancers, 5-8 and in addition, the concurrent inhibition of the mitochondrial electron transport chain creates a synthetic lethal context for GOT1 inhibition. ${ }^{9}$ Collectively, these results illustrate that small molecule inhibitors of GOT1 would be useful tools for studying and ultimately targeting metabolism in PDA and other cancers.

To date, selective small molecule inhibitors of GOT1 do not exist. Accordingly, we performed a high-throughput small molecule screen using a miniaturized GOT1 proteinbased assay. This revealed lead molecules with in vitro GOT1 inhibitory activity. Comparison of these inhibitors to genetic GOT1 knockdown in cell-based proliferation assays and metabolomics studies indicated that the lead GOT1 inhibitors exhibit additional activities that precluded a formal assessment of the GOT1 inhibitory activity in cells. In silico docking, X-ray crystallography, and thermal shift assays using wild type and mutant enzymes were then employed, which suggested, but were unable to formally conclude, that the GOT1 inhibitors act in a PLP-competitive manner. Collectively, these studies describe a new class of GOT1 inhibitors that may ultimately serve as a lead for the development of drugs that target redox balance in pancreatic cancer.

\section{MATERIALS AND METHODS}

\section{Recombinant Protein Expression.}

One Shot BL21 (DE3) Star Escherichia coli competent cells (Thermo Fisher) were transformed with relevant plasmids and inoculated onto Kanamycin Luria Broth/Agar plates. Two hundred milliliter portions of Terrific Broth starter cultures were used to inoculate $6 \times$ $1.5 \mathrm{~L}$ cultures with kanamycin at a concentration of $100 \mu \mathrm{g} / \mathrm{mL}$. Cultures were grown to an $\mathrm{OD}_{600}$ of 0.8 at $37^{\circ} \mathrm{C}$ with shaking at $160 \mathrm{rpm}$ and induced with isopropyl $\beta$-D-1thiogalactopyranoside to a final concentration of $1 \mathrm{mM}$. The temperature of the culture was then decreased to $18{ }^{\circ} \mathrm{C}$, and shaking was continued overnight. Cells were harvested the next day by centrifugation using an F9-6×1000 LEX rotor at $6000 \mathrm{rpm}$ for $10 \mathrm{~min}$ at $4{ }^{\circ} \mathrm{C}$ in a Sorvall Lynx 6000 centrifuge (Thermo Scientific). Bacterial pellets were stored at $-80{ }^{\circ} \mathrm{C}$ until use.

\section{Protein Purification.}

Bacterial pellets were homogenized by being magnetically stirred at $4{ }^{\circ} \mathrm{C}$ in buffer A [ 20 $\mathrm{mM} \mathrm{NaH} 2 \mathrm{PO}_{4}(\mathrm{pH} 7.4)$ and $0.5 \mathrm{M} \mathrm{NaCl}$ ], 1:100 protease inhibitor, 1:100 lysozyme, and 1:10000 universal nuclease for $1 \mathrm{~h}$. Cells were lysed by pulsing sonication with a Branson model 250 sonifier at $50 \%$ power output in $3 \mathrm{~min}$ on/off cycles. The solution was then centrifuged at $16000 \mathrm{rpm}$ for $30 \mathrm{~min}$ using an F20-12×50 LEX rotor at $4{ }^{\circ} \mathrm{C}$ in a Sorvall Lynx 6000 centrifuge (Thermo Scientific). The supernatant was filtered using a $0.45 \mu \mathrm{m}$ PES 
filter. The clarified lysate was passed over a $5 \mathrm{~mL}$ HisTrap HP column (GE Healthcare) using an NGC Quest FPLC system (Bio-Rad) at a flow rate of $1 \mathrm{~mL} / \mathrm{min}$ with buffer A and eluted using a 20 to $500 \mathrm{mM}$ imidazole gradient over 20 column volumes (CV). The absorbance at $280 \mathrm{nM}$ was monitored, and peak elution fractions were collected and concentrated to $2 \mathrm{~mL}$ using an Amicon Ultra-15 centrifugal filter unit with a $10 \mathrm{kDa}$ molecular weight cutoff at $4000 \mathrm{rpm}$ and $4{ }^{\circ} \mathrm{C}$. Material was then injected onto a 16/60 Sephacryl S-200 HR size exclusion column (GE Healthcare) in buffer B [20 mM HEPES (pH 7.5) and $200 \mathrm{mM} \mathrm{NaCl}$. For wild type GOT1 (WT-GOT1), dimeric material was separated from tetrameric material via SEC, to ensure that proteins were monodisperse. Protein was concentrated to $10-20 \mathrm{mg} / \mathrm{mL}$, aliquoted, and flash-frozen in liquid nitrogen for storage until use.

\section{High-Throughput Screening GOT1/GLOX and Counter Screening GOT1/MDH1 Assays.}

GOT1 enzymatic activity was measured utilizing two coupling reactions (Figure 1A,B). For primary screening, GOT1 activity was coupled to aldehyde oxidase 1 (GLOX1) and horseradish peroxidase (HRP). For this reaction, aspartate and a-ketoglutarate $(\mathrm{aKG})$ act as GOT1 substrates and are converted to glutamate and oxaloacetate. The glutamate product serves as a substrate for GLOX1, which is converted to aKG and hydrogen peroxide $\left(\mathrm{H}_{2} \mathrm{O}_{2}\right)$. HRP uses $\mathrm{H}_{2} \mathrm{O}_{2}$ to oxidize nonfluorescent Amplex Red, resulting in the formation of the fluorescent product resorufin that can be readily measured by fluorescence. Using this GLOX1/HRP enzyme-coupled assay, the kinetic parameters and specific activity of recombinant human GOT1 protein were determined and used to optimize a 1536-well platebased HTS end point assay (Figure S1A-K). Library compounds (15 $\mu \mathrm{M}$, DMSO vehicle) at the California Institute for Biomedical Research were screened against GOT1 using nonsaturating (apparent $\left.K_{\mathrm{M}}\right)$ concentrations of aspartate $(4 \mathrm{mM})$ and a-ketoglutarate $(0.5$ $\mathrm{mM}$ ) substrates. Following incubation at $37^{\circ} \mathrm{C}$ for $20 \mathrm{~min}$, at which point the rate of reaction was linear under the defined conditions, the fluorescence (excitation at $544 \mathrm{~nm}$, emission at $590 \mathrm{~nm}$ ) was measured to determine enzyme inhibition activity. The pantransaminase inhibitor amino-oxyacetate (AOA) was used as a positive control ( $Z^{\prime}$ factor $>$ 0.9) (Figure S1L). The nal-concentrations of the components of the assay were as follows: $100 \mathrm{mM}$ HEPES buffer, $100 \mathrm{mM} \mathrm{KCl}, 80 \mathrm{nM}$ GLOX, 0.05 unit/mL HRP, $15 \mathrm{mg} / \mathrm{mL}$ Amplex Red, and $\sim 1 \mathrm{nM}$ GOT1 (adjusted from each purification to produce a 20 min linear reaction). GOT1 inhibition activity was confirmed using a lower-throughput secondary assay in which GOT1 activity is coupled to malate dehydrogenase 1 (MDH1). MDH1 catalyzes the conversion of oxaloacetate to malate using NADH (Figure 1B). As a result, enzyme activity can be monitored by the loss of NADH fluorescence (excitation at $350 \mathrm{~nm}$, emission at $460 \mathrm{~nm}$ ). For this reaction, NADH and MDH1 are added at final concentrations of 250 $\mu \mathrm{M}$ and $0.3 \mu \mathrm{g} / \mathrm{mL}$, respectively.

\section{Cell Lines.}

PaTu8902 pancreatic cancer cells were obtained from DSMZ, and DLD1 colon cancer cells were obtained from ATCC. Both lines were maintained in DMEM with 10\% fetal bovine serum (FBS). Cell lines were validated by STR profiling and routinely tested for mycoplasma contamination using MycoAlert (Lonza). 
PaTu8902 and DLD1 cells were treated overnight with the lentiviral particle-containing 293T supernatant carrying non-targeting (NT) short hairpin (sh)RNAs or those targeting GOT1 (GenBank entry NM_002079) or GOT2 (GenBank entry NM_002080). The next day, the medium was changed and $1 \mu \mathrm{g} / \mathrm{mL}$ puromycin was added for $48 \mathrm{~h}$. Stable lines were employed in the colony-forming assays.

\section{Acute Toxicity Assay.}

Cells were plated in 96-well format at a density of 6000 cells/well. The next day, cells were treated with iGOT1-01 across a dose range (3.125-200 $\mu \mathrm{M})$ for $3 \mathrm{~h}$. Drug-containing media were then removed; fresh drug-free media were added, and cell viability was determined via a Cell Titer Glo (Promega) or Alamar Blue (Invitrogen) assay according to the manufacturer's protocol. For Alamar Blue assays, cells were incubated with Alamar Bluecontaining media for $2 \mathrm{~h}$ at $37^{\circ} \mathrm{C}$ after removal of the drug before the fluorescence was read.

\section{Proliferation Assay.}

PaTu8902 and DLD1 cells were plated in 96-well white-walled plates in growth medium at a density of 500 cells/well. The following day, vehicle (DMSO or PBS), AOA (in PBS), or iGOT1-01 (in DMSO) was added. Cells were grown for 5-8 days and assayed by the Cell Titer Glo (Promega) assay according to the manufacturer's instructions. Cell viability is presented relative to vehicle-treated wells.

\section{Colony-Forming Assay.}

Colony-forming assays (CFAs) were performed as described previously. ${ }^{4} \mathrm{PaTu} 8902$ and DLD1 cells with stable doxycycline-inducible (iDox) shRNAs targeting GOT1, GOT2, or NT were plated into six-well plates at a density of 500 cells/well in triplicate. Doxcontaining $(1 \mu \mathrm{g} / \mathrm{mL})$ medium was added $24 \mathrm{~h}$ after cell seeding, and media (with or without Dox) were replaced with fresh media every $48 \mathrm{~h}$ until the end point. At the end point ( 8 days for PaTu8902, 10 days for DLD1), cells were fixed with pure $\mathrm{MeOH}$ and stained with crystal violet, and colonies were imaged and quantified. GOT1 and GOT2 knockdowns were validated by Western blot analysis.

\section{Western Blot Analysis.}

Stable iDox-shNT, -shGOT1, and -shGOT2 cells were cultured with or without Dox medium, as described for CFAs. On the day that cells were stained in CFA assays, protein lysates were collected with RIPA buffer (Sigma) containing protease inhibitor cocktail (Sigma/Roche) and phosphatase inhibitor (Sigma). Protein samples (10-40 $\mu \mathrm{g}$ ) were resolved on NuPAGE Bis-Tris gels (Invitrogen) and transferred to polyvinylidene fluoride membranes (Millipore). Membranes were blocked in Tris-buffered saline (Bio-Rad) containing 5\% nonfat dry milk (Bio-Rad) and 0.1\% Tween 20 (Sigma) (TBS-T buffer) and incubated with the primary antibody overnight at $4{ }^{\circ} \mathrm{C}$. The membranes were then washed with TBS-T buffer followed by exposure to the appropriate HRP-conjugated secondary antibody for $1 \mathrm{~h}$ and visualized on film (GeneMate) using enhanced chemiluminescence (ECL) detection (Amersham). The following antibodies were used: anti-aspartate aminotransferase (anti-GOT1) at a 1:1000 dilution (Abcam, ab17193), anti-GOT2 at a 
1:1000 dilution (Abcam, ab171739), and loading control vinculin at a 1:10000 dilution (Cell Signaling). The anti-rabbit IgG, HRP-linked secondary antibody (Cell Signaling) was used at a 1:10000 dilution and hybridized for $1 \mathrm{~h}$ at room temperature.

\section{Metabolomics Analysis.}

Isotope tracing metabolomic analysis was performed as described previously. ${ }^{10}$ Briefly, PaTu8902 cells were grown as detailed above and then transferred into glutamine-free (with $10 \mathrm{mM}$ glucose) DMEM containing 10\% dialyzed FBS and supplemented with $2 \mathrm{mM}$ [U- ${ }^{13} \mathrm{C}$ ]glutamine overnight. Polar metabolites were extracted with $2 \mathrm{~mL}$ of a $\mathrm{MeOH} / \mathrm{H}_{2} \mathrm{O}$ mixture (4:1) for $30 \mathrm{~min}$ on dry ice, scraped, transferred to $2 \mathrm{~mL}$ tubes, and centrifuged (30 $\min$ at $21000 \mathrm{~g}$ ), and the supernatants were dried under vacuum. Samples were resuspended in $15 \mu \mathrm{L}$ of high-performance liquid chromatography grade water. Five micro-liters of each sample was injected and analyzed using a 5500 QTRAP triple-quadrupole mass spectrometer (AB/Sciex) coupled to a Prominence UFLC system (Shimadzu).

\section{GOT1/GLOX Assay for Specific Activity.}

GOT1 or mutant GOT1 protein ( $300 \mathrm{ng}$ ) was preincubated at $37^{\circ} \mathrm{C}$ in a buffer containing $200 \mathrm{mM}$ HEPES (pH 7.4) and $200 \mathrm{mM} \mathrm{KCl}$. A separate reaction mix containing $4 \mathrm{mM}$ aspartate, $0.5 \mathrm{mM} \mathrm{aKG}, 80 \mathrm{nM}$ GLOX, 0.5 unit of HRP (Sigma-Aldrich), and $1.285 \mu \mathrm{g}$ of Amplex Red Reagent (Invitrogen) was also prepared and prewarmed at $37{ }^{\circ} \mathrm{C}$. WT-GOT1 or mutants were then added to the reaction mix to bring the final volume to $100 \mu \mathrm{L}$. The production of resorufin was measured kinetically using a Tecan I-control Infinite 200 Pro plate (excitation at $544 \mathrm{~nm}$, emission at $590 \mathrm{~nm}$ ) for $15 \mathrm{~min}$ with $15 \mathrm{~s}$ interval reads. To relate $\mathrm{H}_{2} \mathrm{O}_{2}$ to relative fluorescence units (RFU), an $\mathrm{H}_{2} \mathrm{O}_{2}$ dilution series was generated from $16.6 \mathrm{pg}$ to $8.5 \mathrm{ng}$ in $200 \mathrm{mM}$ HEPES (pH 7.4) and $200 \mathrm{mM} \mathrm{KCl}$. The dilution series was added to the Amplex Red reaction mix supplemented with $4 \mathrm{mM}$ aspartate and $0.5 \mathrm{mM}$ aKG, dispensed into a 96-well plate, and incubated in the dark for $5 \mathrm{~min}$ at $37^{\circ} \mathrm{C}$, at which point a single end point read was taken. Interpolation using the $\mathrm{H}_{2} \mathrm{O}_{2}$ standard curve was used to determine velocities (micromolar per minute per milligram) for WT-GOT1 or mutant GOT1 enzymes.

\section{In Silico Modeling.}

Docking was performed using the WT-GOT1 crystal structure [Protein Data Bank (PDB) entry 3II0]. Model coordinates were prepared for docking using the protein preparation wizard within Maestro 11 by adding hydrogens and generating protonation states using EPIK at $\mathrm{pH} 7.0 \pm 2.0 .{ }^{11-13}$ Hydrogen bond assignments and torsion angles were optimized using PROPKA, and a restrained minimization was performed using the OPLS3 force field. 14-17 Ligands were prepared with LIGPREP from SMILES using an OPLS3 force field modified using EPIK. ${ }^{11-13,15-18}$ Molecules were desalted and featured all tautomers. A glide grid of $8000 \AA^{3}$ was centered on residues previously identified as being near the PLP binding site, including F19, E142, and D223 as identified in the GOT1 crystal structure. Glide docking was performed using the SP protocol. ${ }^{19}$ Ligand poses were evaluated on the basis of Emodel and Glide scores. 


\section{Protein Crystallization.}

Novel crystallization conditions were obtained for WT-GOT1 at $16 \mathrm{mg} / \mathrm{mL}$ by sparse matrix screening using a 1:1 ratio of protein to mother liquor via sitting drop vapor diffusion (Figure S2). An initial crystallization hit of $25 \%$ (w/v) polyethylene glycol 3350 and $0.1 \mathrm{M}$ sodium acetate trihydrate ( $\mathrm{pH} 4.5)$ was identified after $48 \mathrm{~h}$ at $21^{\circ} \mathrm{C}$. The hit was further optimized by additive screening. Final crystallization conditions included 5\% Cymal. ${ }^{20}$ Cryoprotected crystals were soaked in mother liquor supplemented with $20 \%$ glycerol and flash-frozen in liquid nitrogen.

T110A (30 mg/mL) mutant crystals were grown using the same method as described above (Figure S2). Crystals were nucleated in a mother liquor of $25 \%$ (w/v) polyethylene glycol 3350 and $0.1 \mathrm{M} \mathrm{HEPES}$ (pH 7.5) after $48 \mathrm{~h}$ at $21^{\circ} \mathrm{C}$. Cryoprotected crystals were soaked in mother liquor supplemented with $20 \%$ ethylene glycol and flash-frozen in liquid nitrogen.

T110A/S256A (38 mg/mL) mutant crystals were nucleated from a solution containing $20 \%$ (w/v) polyethylene glycol monomethyl ether 2000, 0.1 M Tris (pH 8.5), and 0.2 M trimethylamine $\mathrm{N}$-oxide dehydrate after $48 \mathrm{~h}$ at $21{ }^{\circ} \mathrm{C}$ (Figure S2). To increase size, crystals were microseeded using the dilution method. ${ }^{21}$ Cryo-protected crystals were soaked in mother liquor supplemented with $20 \%$ glycerol and flashfrozen in liquid nitrogen.

Several attempts were made to obtain an iGOT1-074-8- bound structure using cocrystallization and soaking. Crystals were soaked with iGOT1-074-8 over a concentration range of $0.15-0.3 \mathrm{mM}$ for $5 \mathrm{~h}$ to 7 days and then analyzed for diffraction. Ultimately, we were not able to successfully generate inhibitor-bound crystals for any of the GOT1 proteins.

\section{Structure Determination and Analysis.}

Diffraction data were collected at the APS (Argonne National Laboratory, Lemont, IL) using LS-CAT 21. Multiple data sets were collected using a MAR300 and Dectris Eiger 9M detectors at a wavelength of $1.00 \AA$ and $100 \mathrm{~K}$. Diffraction data were indexed, processed, and scaled using the HKL2000 software suite. ${ }^{22,23}$ Structures were determined by molecular replacement using MOLREP with WT-GOT1 (PDB entry 3II0) as the search model. ${ }^{24,25}$ The models were built and refined using REFMAC5 followed by placement of water molecules using COOT. ${ }^{23,26,27}$ T110A-GOT1 diffraction data showed twinning, and the structure was determined using detwinning methods and restrained refinement within the CCP4 suite. ${ }^{23}$ In the T110A/S256A mutant structure, no density was observed for iGOT1-074-8. The final model statistics are listed in Table 1.

\section{Thermal Shift Assays.}

WT-GOT1 and its derived mutants bat $1 \mathrm{mg} / \mathrm{mL}$ were mixed in a 1000:1 ratio with Sypro Orange dye (Sigma-Aldrich) and plated. Samples were processed using a Bio-Rad CFX C100 Touch quantitative polymerase chain reaction and run using the FRET assay settings with a heating ramp of $0.3{ }^{\circ} \mathrm{C} / \mathrm{s}$ cycling from 4 to $100{ }^{\circ} \mathrm{C}$. Analysis was performed using the Bio-Rad CFX Manager Software (version 3.1, Bio-Rad). 


\section{RESULTS}

\section{Identification of Novel GOT1 Inhibitors.}

A library of 800000 small molecules was screened in single-point format at $15 \mu \mathrm{M}$ (Figure $\mathrm{S} 3$ ) in the GOT1/GLOX/HRP assay (Figure 1A). ${ }^{28}$ Setting a threshold $Z$ score of -3 , corresponding to at least 50\% GOT1 inhibition, gave a $0.1 \%$ hit rate and resulted in 850 hits. These putative hits were first confirmed in triplicate and then counter-screened against GLOX/HRP. Compounds with inhibitory activities in the GLOX/HRP assay similar to those in the GOT1/GLOX/HRP assay were assumed to be false positives that inhibited the coupling enzymes. From these collective efforts, we identified the hit compound iGOT1-01 (Figure 1C and Figure S3), which had an $\mathrm{IC}_{50}$ of $11.3 \mu \mathrm{M}$ in the GOT1/GLOX/HRP assay (Figure 1D). This was $\sim 3$-fold more potent than its activity in the GLOX/HRP assay [31.5 $\mu \mathrm{M}$ (Figure S4A)].

GOT1 and GLOX can both utilize glutamate, which was assumed to account for the activity of iGOT1-01 in the GLOX/HRP assay. To examine the GOT1 inhibitory activity of iGOT1-01 in the absence of GLOX, we developed an additional GOT1 assay that employs malate dehydrogenase 1 (MDH1) as the coupling enzyme (Figure 1B). In this assay, the oxaloacetate product from the GOT1 reaction is the substrate for MDH1, which oxidizes NADH to NAD ${ }^{+}$. The loss of NADH fluorescence is used as a readout of GOT1 activity. In the GOT1/MDH1 assay, iGOT1-01 had an $\mathrm{IC}_{50}$ of $84.6 \mu \mathrm{M}$ (Figure S4B). No inhibitory activity was observed for iGOT1-01 against MDH1 alone at $100 \mu \mathrm{M}$ (Figure S4C).

We then used mass spectrometry-based metabolomics approaches to monitor changes in cellular metabolism associated with the GOT1 inhibitory activity of iGOT1-01. To this end, we first determined the maximal concentration of the inhibitor that cells would tolerate over a $3 \mathrm{~h}$ period. The $3 \mathrm{~h}$ time point represents the length of time required to turn over the intracellular pool of the GOT1 substrate aspartate, whose accumulation we previously illustrated to provide a robust readout for GOT1 inhibition. ${ }^{4}$ Application of iGOT1-01 to a pancreatic cancer cell line (PaTu8902) and a colon cancer cell line (DLD1) at the largest soluble dose $(200 \mu \mathrm{M})$ for $3 \mathrm{~h}$ revealed little to no toxicity using two readouts of cell viability (Figure 2A,B).

In pancreatic cancer cells grown in culture, our previous results using nonradioactive carbon $13\left({ }^{13} \mathrm{C}\right)$-labeled glutamine metabolomic profiling illustrated that GOT1 substrate aspartate is predominantly derived from glutamine. ${ }^{4}$ In addition, we demonstrated that shRNAmediated GOT1 knockdown led to the accumulation of aspartate and predominantly the $\mathrm{M}$ +4 isotopologue of aspartate. Thus, to analyze the GOT1 inhibitory activity of iGOT1-01 in cells, we used [13C]glutamine tracing metabolomics and followed glutamine-derived aspartate, specifically, and the glutamine-derived metabolome, generally, in PaTu8902 cells across range of iGOT1-01 concentrations (Figure 2C-E). Nonsupervised hierarchical clustering of the $\left[{ }^{13} \mathrm{C}\right]$ glutamine tracing metabolomics data revealed widespread changes to the glutamine-derived metabolome at $200 \mu \mathrm{M}$ iGOT1-01 (Figure 2C). This was not observed for smaller doses, which all cluster with the vehicle-treated cells. Glutamine-derived metabolites from cells treated with the small molecule pan-transaminase control AOA 
clustered independently of those from iGOT1-01-treated cells with one important exception, aspartate isotopologues.

In pancreatic cancer cells, inhibition of GOT1 preferentially leads to accumulation of the M +4 aspartate isotopologue from $\left[{ }^{13} \mathrm{C}\right]$ glutamine. In contrast, inhibition of GOT2 (the mitochondrial GOT isoform) leads to a drop in the level of $\mathrm{M}+4$ aspartate, as aspartate is the product of the GOT2-mediated reaction. Because GOT2 is upstream of GOT1 in pancreatic cancer glutamine metabolism, dual GOT1/GOT2 inhibition is reflected by a GOT2 inhibition signature. ${ }^{4}$ This is evident using the pan-transaminase inhibitor and positive control AOA (Figure 2E and Figure S5A). Indeed, we observed that iGOT1-01 treatment of pancreatic cancer cells led to a drop in the level of all aspartate isotopologues, in a manner similar to that seen with AOA (Figure 2E). Thus, these data suggest iGOT1-01 also has GOT2 inhibitory activity in cells. Because GOT2 inhibition precludes the assessment of GOT1 inhibition, we were unable to determine the degree of GOT1 inhibitory activity in cells using this assay. Next, we tested the growth inhibitory potential of iGOT1-01 in PaTu8902 and DLD1 cells (Figure 2F) and compared it to that of AOA (Figure 2G).

DLD1 cells were more sensitive to both inhibitors. Previously, we demonstrated the growth of pancreatic cancer cells was repressed following shRNA-mediated inhibition of GOT1 or GOT2. ${ }^{4}$ In contrast, here we found that the growth of DLD1 cells was not impacted by GOT1 or GOT2 knockdown (Figure 2H-K and Figure S5B-G). Given that iGOT1-01 behaved more like AOA in terms of its impact on the metabolome (Figure 2C) and cellular selectivity (Figure 2F,G), these data suggest that dual inhibition of GOT1 and GOT2 in cells exhibits a profile different from that of single-isoform inhibition. Alternatively, because at large doses growth of both cell lines was fully inhibited, pleiotropic inhibitory activity against multiple transaminases or PLP-dependent enzymes may account for these results.

\section{In Silico Analysis.}

Given the high concentration of iGOT1-01 required in cells and the observed incongruence with the isoform-selective shRNA experiments, we set forth to analyze how our lead scaffold was interacting with GOT1. Such insight could be used to identify regions on the molecule that could be optimized for isoform selectivity by medicinal chemistry-based approaches. For the in silico analysis, we opted to use iGOT1-790-5, which was determined to be a modestly more potent iGOT1-01 analogue (Figure S6A,B).

On the basis of our in silico studies, the top pose $(-9.6 \mathrm{kcal} / \mathrm{mol})$ suggested that iGOT1-790-5 bound competitively within the pyridoxal $5^{\prime}$-phosphate (PLP) site (Figure 3). As a baseline comparator, PLP was docked with the top pose yielding a score of $-8.1 \mathrm{kcal} /$ mol, suggesting that the predicted pose of iGOT1-790-5 was significant. Several interactions were predicted between GOT1 and iGOT1-790-5, including hydrogen bonding among Tyr226, Trp141, Asp223, Asn195, and Gly39, three of which were also reported to bind PLP. ${ }^{29,30}$ In this structure, PLP displayed polar contacts with Trp141, Asp223, Tyr226, Gly109, Thr110, Ser256, Phe257, and Lys259. 


\section{Kinetic Analysis.}

To eliminate the competition between iGOT1-790-5 and endogenous PLP, a series of mutants were designed (T110A, S256A, and T110A/S256A) to ablate PLP binding and open the active site for iGOT1-790-5. Residues were chosen that had side-chain polar contacts with the PLP phosphate and did not appear to play a role in the docked pose of iGOT1-790-5. Additionally, we postulated that reducing the overall polar surface area of the GOT1 active site may be beneficial for the binding of iGOT1-790-5 because of its hydrophobicity. It is noteworthy that we did not select to mutate the active site lysine residue (Lys259), which covalently binds and holds PLP and would formally preclude PLP binding, based on the notion that Lys 259 is much closer to interactions that may be essential to iGOT1-790-5 binding.

Next, we generated and analyzed the activity of the mutant GOT1 structures, relative to that of WT-GOT1. Our results showed that WT-GOT1 was active, albeit with a specific activity $\left(27.1 \mu \mathrm{mol} \mathrm{min}{ }^{-1} \mathrm{mg}^{-1}\right)$ that was lower than the literature value $\left(70.83 \mu \mathrm{mol} \mathrm{min}{ }^{-1} \mathrm{mg}^{-1}\right){ }^{31}$ The relative activities of GOT1 mutants, compared to that of the wild type enzyme, were determined by comparison of the specific activity at the apparent $K_{\mathrm{M}}$ of each substrate. Each single mutant appeared to retain partial activity. The T110A mutant trended toward being less active than the S256A mutant; however, the difference between the two was not significant (Figure 4). We interpreted this to mean that each single mutant retained some degree of binding to PLP, although the affinity for PLP was decreased substantially. Furthermore, introduction of the double mutant T110A/S256A completely ablated enzyme activity and allowed us to assume there was no PLP bound in the active site (Figure 4 and Figure S6C,D).

\section{X-ray Structure Analysis.}

We performed X-ray protein co-crystallographic studies using wild type and mutant variants of GOT1 and a GOT1 inhibitor further optimized for solubility and into which bromine was substituted to facilitate phase determination [iGOT1-074-8 (Figure S6E)]. Initial efforts with the wild type protein failed to yield a co-crystal structure with electron density corresponding to bound iGOT1-074-8. On the basis of relative catalytic activities, we predicted that the T110A/S256A double mutant would not possess bound endogenous PLP and that this would facilitate the observation of iGOT1-074-8 bound within the GOT1 PLP binding site. Efforts to co-crystallize either the T110A or S256A single mutant with iGOT1-074-8 resulted in structures that contained electron density within the PLP binding site corresponding to bound PLP but not the iGOT1-074-8 ligand. Consistent with the observed ablation of catalytic activity displayed by the T110A/S256A double mutant (Figure 4), efforts to co-crystallize this form of the protein resulted in a structure that lacked electron density within the PLP binding site that would correspond to either a bound molecule of PLP or the iGOT1-074-8 ligand. Presumably, the transient and/or low-affinity nature of the GOT1-iGOT1-074-8 interaction precluded observation of the bound state of this interaction. Crystal structure statistics are listed in Table 1.

The WT-GOT1 structure is a homodimer, each of which contains PLP. An overlay of the monomers reveals a high degree of similarity with a RMSD of $0.14 \AA$ (Figure S7A). 
Similarly, WT and T110A mutant structures share a high degree of structural similarity [RMSD of $0.50 \AA$ (Figure S7B)]. In contrast to that of WT-GOT1, the structure of the T110A mutant has six monomers in the asymmetric unit with partial density for the PLP cofactor in the active site (Figure S7C). Overall, each chain and their PLP cofactors are highly similar [RMSD of $0.15-0.23 \AA$ (Figure S7D)]. In the double mutant structure, there is only one monomer per asymmetric unit, also with a high degree of structural similarity to WT-GOT1, yet without bound PLP [RMSD of $0.35 \AA$ A (Figure 5A and Figure S8)].

Overall, the structural results support the enzymatic activity data (Figures 4 and 5 and Figures S7 and S8). We observed lower activity for the T110A mutant protein than for the WT protein, which correlated with a decrease in the electron density for PLP in the T110A mutant when compared to WT (Figure 5B,C). In the double mutant structure, there was no density for PLP, confirming the abolishment of enzymatic activity (Figure 5D).

\section{Thermal Shift Assay and Compound Titration.}

Thermal shift assays (TSA) were utilized to biophysically characterize recombinant human WT-GOT1 and its mutants. The assay functions by protein denaturation over a temperature gradient, where during protein unfolding, exposed hydrophobic regions bind a dye and fluoresce due to solvent relaxation effects. The melting profile of WT-GOT1 displayed multiple peaks (dRFU/d $t$ vs temperature), with major peaks at 50,60 , and $70{ }^{\circ} \mathrm{C}$, indicative of multiple species in solution or loosely associated domains (Figure 6A). Size exclusion chromatography (SEC) provided supporting evidence for both a dimeric species and a tetrameric species in solution for the WT protein (Figure S9A). Dimeric and tetrameric species were separated and again subjected to protein melting, both yielding identical profiles, indicating an active equilibrium (data not shown).

In contrast to the WT protein, the T110A and S256A mutants were observed by SEC to be exclusively dimeric in solution (Figure S9A). Via comparison of the TSA results of GOT1 variants (in the absence of iGOT1-074-8), both T110A and S256A GOT1 mutants displayed a minor melting peak near $40^{\circ} \mathrm{C}$, likely corresponding to apoprotein, free of PLP (Figure $6 \mathrm{~A})$. The major peak for both single mutants melted at a much higher temperature, near $70{ }^{\circ} \mathrm{C}$. This species likely corresponds to PLP-bound GOT1. Further supporting this hypothesis, the melting profile for the T110A/S256A mutant displayed a single uniform melting peak at $41.5^{\circ} \mathrm{C}$ (Figure 6A). A titration of T110A/S256A with PLP at high concentrations shifted the melting profile from 40 to $70{ }^{\circ} \mathrm{C}$, supporting the assignment of these peaks as the PLP-unbound and -bound forms (Figure 6B).

WT-GOT1 and its mutants were also assessed in the presence of iGOT1-074-8. For WTGOT1, the addition of iGOT1-074-8 stabilized the protein, shifting the thermal profile toward a single peak at $72{ }^{\circ} \mathrm{C}$ (Figure 6C). Importantly, this result supported the conclusion that iGOT1-074-8 directly binds GOT1. For both single mutants, increasing concentrations of iGOT1-074-8 increase the peak intensity for the unbound state at $40{ }^{\circ} \mathrm{C}$, supporting the hypothesis that iGOT1-074-8 acts through displacement of PLP (Figure 6D,E). However, it did not appear that iGOT1-074-8 fully displaced PLP in this experiment, as the bound form is still observed. Addition of iGOT1-074-8 to the double mutant appeared as a small shoulder peak at $47^{\circ} \mathrm{C}$ (Figure 6F), supporting the notion that iGOT1-074-8 binds the 
enzyme directly and does not have the requirement for a transitional GOT1—PLP complex. Overall, the thermal analysis supports the binding of iGOT1-074-8 to GOT1 through the displacement of PLP; however, this interaction is likely transient or weak as we did not observe full conversion of the target to anunbound PLP state (Figure 6 and Figure S9B-F).

\section{DISCUSSION}

Pancreatic cancer cells depend on the GOT1 pathway for survival and growth, and the targeting of this pathway may provide new, selective drugs. We ran an HTS campaign for GOT1 inhibitors and identified iGOT1-01 as a micromolar inhibitor of GOT1 (Figure 1C and Figure S3). Glutamine carbon tracing experiments using mass spectrometry-based metabolomics indicated that iGOT1-01 inhibited GOT2 (Figure 2), which precluded an analysis of the GOT1 inhibitory activity because GOT2 is upstream of GOT1 in glutamine metabolism. ${ }^{4}$ Pancreatic cancer cells are also dependent on GOT2 activity, and a dual GOT1/2 inhibitor may have additional utility. Indeed, GOT1 and GOT2 share complete conservation of the active site moieties that interact with PLP (Figure S10) and potentially the inhibitors described herein. In addition, dependence on GOT activity is a feature of several types of cancer, and inhibition of mitochondrial metabolism sensitizes cancer cells to GOT inhibition. ${ }^{5-9}$ Nevertheless, the GOT2 inhibitory activity and perhaps additional transaminase or PLP-dependent enzyme off-target activities of iGOT1-01 indicate that a more selective inhibitor will be necessary to test the activity of GOT1 inhibition in preclinical pancreatic cancer models. To this end, the iGOT1-01 drug scaffold may provide a useful starting point. $^{28}$

In GOT1, multiple hydrogen bond networks (direct and extended) are coupled to the phosphate pyridinyl nitrogen and 3-hydroxy of PLP, inducing its electrophilicity. Residues Thr110 and Ser256 face the phosphate group. Lys259 faces the PLP aldehyde to form a Schiff base making an internal aldimine. Residues Tyr226 and Asp195 make hydrogen bonds to the PLP hydroxyl group. Asp223 makes a hydrogen bond to the pyridinyl nitrogen of the PLP cofactor. Altogether, these interactions result in the activation and stabilization of PLP (Figure 5B). As previously described, an extended hydrogen bond network involving residues Asp222, His143, and His189 and water molecules affects the protonation state of the PLP pyridine nitrogen and its activation. ${ }^{29,30}$ Herein, we demonstrate PLP binding can be disrupted by disturbing the hydrogen bond network within the phosphate group, either partially or entirely, resulting in reduced or ablated GOT1 enzymatic activity.

It was interesting to note that single mutation of either Thr110A or Ser256A resulted in an altered oligomeric state of the protein, eliminating the tetrameric species compared to the WT protein. While these residues reside near the dimer interface, they do not directly disrupt dimerization. Comparing the structure of T110A or T110A/S256A to that of the WT does reveal a shift in the C-terminal helix (371-411) that sits at the dimer interface of tetrameric WT-GOT1 (Figure S8B).

The mutational studies have provided evidence for the displacement of PLP by iGOT1-074-8 (Figure 6). Addition of iGOT1-074-8 to either the S256A or T110A mutant results in a melting profile that mimics the PLP-free state for the T110A/S256A mutant. 
Docking results support the finding that iGOT1-074-8 operates through direct competition for the active site. These results are tempered by an inability to generate a compound-bound crystal structure in any of these trials. Future studies will be required to enhance compound affinity.

\section{Supplementary Material}

Refer to Web version on PubMed Central for supplementary material.

\section{Acknowledgments}

Funding

C.A.L. was supported by a Pancreatic Cancer Action Network/ AACR Pathway to Leadership award (13-70-25LYSS), Dale F. Frey Award for Breakthrough Scientists from the Damon Runyon Cancer Research Foundation (DFS-09-14), a Junior Scholar Award from The V Foundation for Cancer Research (V2016-009), a Kimmel Scholar Award from the Sidney Kimmel Foundation for Cancer Research (SKF-16-005), a Cancer Center Support Grant (P30 CA046592), a 2016 AACR-Bayer Innovation and Discovery Grant (16-80-44-LYSS), and a 2017 AACR NextGen Grant for Transformative Cancer Research (17-20-01-LYSS). Metabolomics studies performed at the University of Michigan were supported by National Institutes of Health Grant DK097153, the Charles Woodson Research Fund, and the UM Pediatric Brain Tumor Initiative. Additionally, this work was supported by a Lustgarten Foundation grant to A.C.K., L.C.C., and L.L.L. L.C.C. is funded by Grant R35-CA197588. D.M.K. is supported by the University of Michigan's Program in Chemical Biology Graduate Assistance in Areas of National Need (GAANN) award.

\section{ABBREVIATIONS}

\begin{tabular}{|c|c|}
\hline GOT1 & glutamate oxaloacetate transaminase 1 \\
\hline PDA & pancreatic ductal adenocarcinoma \\
\hline PLP & pyridoxal 5-phosphate \\
\hline ROS & reactive oxygen species \\
\hline GSH & glutathione \\
\hline ITPG & isopropyl $\beta$-D-1-thiogalactopyranoside \\
\hline AOA & amino-oxyacetate \\
\hline SEC & size exclusion chromatography \\
\hline HTS & high-throughput screening \\
\hline GLOX & glutamate oxidase \\
\hline HRP & horseradish peroxidase \\
\hline MDH1 & malate dehydrogenase 1 \\
\hline FBS & fetal bovine serum \\
\hline CFA & colony-forming assay \\
\hline ECL & enhanced chemilumine-scence \\
\hline
\end{tabular}


RMSD root-mean-square deviation

\section{REFERENCES}

(1). Siegel RL, Miller KD, and Jemal A (2016) Cancer statistics, 2016. Ca-Cancer J. Clin 66, 7-30. [PubMed: 26742998]

(2). Vaccaro V, Sperduti I, and Milella M (2011) FOLFIRINOX versus gemcitabine for metastatic pancreatic cancer. N. Engl. J. Med 365, 768-769. [PubMed: 21864184]

(3). Halbrook CJ, and Lyssiotis CA (2017) Employing Metabolism to Improve the Diagnosis and Treatment of Pancreatic Cancer. Cancer Cell 31, 5-19. [PubMed: 28073003]

(4). Son J, Lyssiotis CA, Ying H, Wang X, Hua S, Ligorio M, Perera RM, Ferrone CR, Mullarky E, Shyh-Chang N, Kang Y, Fleming JB, Bardeesy N, Asara JM, Haigis MC, DePinho RA, Cantley LC, and Kimmelman AC (2013) Glutamine supports pancreatic cancer growth through a KRASregulated metabolic pathway. Nature 496, 101-105. [PubMed: 23535601]

(5). Feld FM, Nagel PD, Weissinger SE, Welke C, Stenzinger A, Möller P, and Lennerz JK (2015) GOT1/AST1 expression status as a prognostic biomarker in pancreatic ductal adenocarcinoma. Oncotarget 6, 4516-4526. [PubMed: 25595905]

(6). Yang CS, Stampouloglou E, Kingston NM, Zhang L, Monti S, and Varelas X (2018) Glutamineutilizing transaminases are a metabolic vulnerability of TAZ/YAP-activated cancer cells. EMBO Rep 19, No. e43577.

(7). Gaglio D, Metallo CM, Gameiro PA, Hiller K, Danna LS, Balestrieri C, Alberghina L, Stephanopoulos G, and Chiaradonna F (2011) Oncogenic K-Ras decouples glucose and glutamine metabolism to support cancer cell growth. Mol. Syst. Biol 7, 523. [PubMed: 21847114]

(8). Thornburg JM, Nelson KK, Clem BF, Lane AN, Arumugam S, Simmons A, Eaton JW, Telang S, and Chesney J (2008) Targeting aspartate aminotransferase in breast cancer. Breast Cancer Res 10, R84. [PubMed: 18922152]

(9). Birsoy K, Wang T, Chen WW, Freinkman E, Abu-Remaileh M, and Sabatini DM (2015) An Essential Role of the Mitochondrial Electron Transport Chain in Cell Proliferation Is to Enable Aspartate Synthesis. Cell 162, 540-551. [PubMed: 26232224]

(10). Sousa CM, Biancur DE, Wang X, Halbrook CJ, Sherman MH, Zhang L, Kremer D, Hwang RF, Witkiewicz AK, Ying H, Asara JM, Evans RM, Cantley LC, Lyssiotis CA, and Kimmelman AC (2016) Pancreatic stellate cells support tumour metabolism through autophagic alanine secretion. Nature 536, 479-483. [PubMed: 27509858]

(11). Greenwood JR, Calkins D, Sullivan AP, and Shelley JC (2010) Towards the comprehensive, rapid, and accurate prediction of the favorable tautomeric states of drug-like molecules in aqueous solution. J. Comput.-Aided Mol. Des 24, 591-604. [PubMed: 20354892]

(12). Shelley JC, Cholleti A, Frye LL, Greenwood JR, Timlin MR, and Uchimaya M (2007) Epik: a software program for $\mathrm{pK}$ a prediction and protonation state generation for drug-like molecules. J. Comput.-Aided Mol. Des 21, 681-691. [PubMed: 17899391]

(13). Madhavi Sastry G, Adzhigirey M, Day T, Annabhimoju R, and Sherman W (2013) Protein and ligand preparation: parameters, protocols, and influence on virtual screening enrichments. J. Comput.-Aided Mol. Des 27, 221-234. [PubMed: 23579614]

(14). Harder E, Damm W, Maple J, Wu C, Reboul M, Xiang JY, Wang L, Lupyan D, Dahlgren MK, Knight JL, Kaus JW, Cerutti DS, Krilov G, Jorgensen WL, Abel R, and Friesner RA (2016) OPLS3: A Force Field Providing Broad Coverage of Drug-like Small Molecules and Proteins. J. Chem. Theory Comput 12, 281-296. [PubMed: 26584231]

(15). Jorgensen WL, Maxwell DS, and Tirado-Rives J (1996) Development and Testing of the OPLS All-Atom Force Field on Conformational Energetics and Properties of Organic Liquids. J. Am. Chem. Soc 118, 11225-11236.

(16). Jorgensen WL, and Tirado-Rives J (1988) The OPLS [optimized potentials for liquid simulations] potential functions for proteins, energy minimizations for crystals of cyclic peptides and crambin. J. Am. Chem. Soc 110, 1657-1666. [PubMed: 27557051] 
(17). Shivakumar D, Williams J, Wu Y, Damm W, Shelley J, and Sherman W (2010) Prediction of Absolute Solvation Free Energies using Molecular Dynamics Free Energy Perturbation and the OPLS Force Field. J. Chem. Theory Comput 6, 1509-1519. [PubMed: 26615687]

(18). Harder E, Damm W, Maple J, Wu C, Reboul M, Xiang JY, Wang L, Lupyan D, Dahlgren MK, Knight JL, Kaus JW, Cerutti DS, Krilov G, Jorgensen WL, Abel R, and Friesner RA (2016) OPLS3: A Force Field Providing Broad Coverage of Drug-like Small Molecules and Proteins. J. Chem. Theory Comput 12, 281-296. [PubMed: 26584231]

(19). Friesner RA, Banks JL, Murphy RB, Halgren TA, Klicic JJ, Mainz DT, Repasky MP, Knoll EH, Shelley M, Perry JK, Shaw DE, Francis P, and Shenkin PS (2004) Glide: A New Approach for Rapid, Accurate Docking and Scoring. 1. Method and Assessment of Docking Accuracy. J. Med. Chem 47, 1739-1749. [PubMed: 15027865]

(20). Gray DN (1997) U.S. Patent 5,674,987.

(21). D’Arcy A, Bergfors T, Cowan-Jacob SW, and Marsh M (2014) Microseed matrix screening for optimization in protein crystallization: what have we learned? Acta Crystallogr., Sect. F: Struct. Biol. Commun 70, 1117-1126. [PubMed: 25195878]

(22). Otwinowski Z, and Minor W (1997) Processing of X-ray Diffraction Data Collected in Oscillation Mode. Methods Enzymol 276, 307-326.

(23). Winn MD, Ballard CC, Cowtan KD, Dodson EJ, Emsley P, Evans PR, Keegan RM, Krissinel EB, Leslie AG, McCoy A, McNicholas SJ, Murshudov GN, Pannu NS, Potterton EA, Powell HR, Read RJ, Vagin A, and Wilson KS (2011) Overview of the CCP4 suite and current developments. Acta Crystallogr., Sect. D: Biol. Crystallogr 67, 235-242. [PubMed: 21460441]

(24). Vagin A, and Teplyakov A (2010) Molecular replacement with MOLREP. Acta Crystallogr., Sect. D: Biol. Crystallogr 66, 22-25. [PubMed: 20057045]

(25). Vagin A, and Teplyakov A (1997) MOLREP: an Automated Program for Molecular Replacement. J. Appl. Crystallogr 30, 1022-1025.

(26). Emsley P (2017) Tools for ligand validation in Coot. Acta Crystallogr. D Struct Biol 73, $203-$ 210. [PubMed: 28291755]

(27). Murshudov GN, Skubak P, Lebedev AA, Pannu NS, Steiner RA, Nicholls RA, Winn MD, Long F, and Vagin AA (2011) REFMAC5 for the refinement of macromolecular crystal structures. Acta Crystallogr., Sect. D: Biol. Crystallogr 67, 355-367. [PubMed: 21460454]

(28). Anglin J, Zavareh RB, Sander PN, Haldar D, Mullarky E, Cantley LC, Kimmelman AC, Lyssiotis CA, and Lairson LL (2018) Discovery and optimization of aspartate aminotransferase 1 inhibitors to target redox balance in pancreatic ductal adenocarcinoma. Bioorg. Med. Chem. Lett 28, 2675-2678. [PubMed: 29731362]

(29). Dajnowicz S, Johnston RC, Parks JM, Blakeley MP, Keen DA, Weiss KL, Gerlits O, Kovalevsky A, and Mueser TC (2017) Direct visualization of critical hydrogen atoms in a pyridoxal $5^{\prime}$ phosphate enzyme. Nat. Commun 8, 955. [PubMed: 29038582]

(30). Dajnowicz S, Parks JM, Hu X, Gesler K, Kovalevsky AY, and Mueser TC (2017) Direct evidence that an extended hydrogen-bonding network influences activation of pyridoxal $5^{\prime}$-phosphate in aspartate aminotransferase. J. Biol. Chem 292, 5970-5980. [PubMed: 28232482]

(31). Jiang X, Chang H, and Zhou Y (2015) Expression, purification and preliminary crystallographic studies of human glutamate oxaloacetate transaminase 1 (GOT1). Protein Expression Purif 113, 102-106. 
A

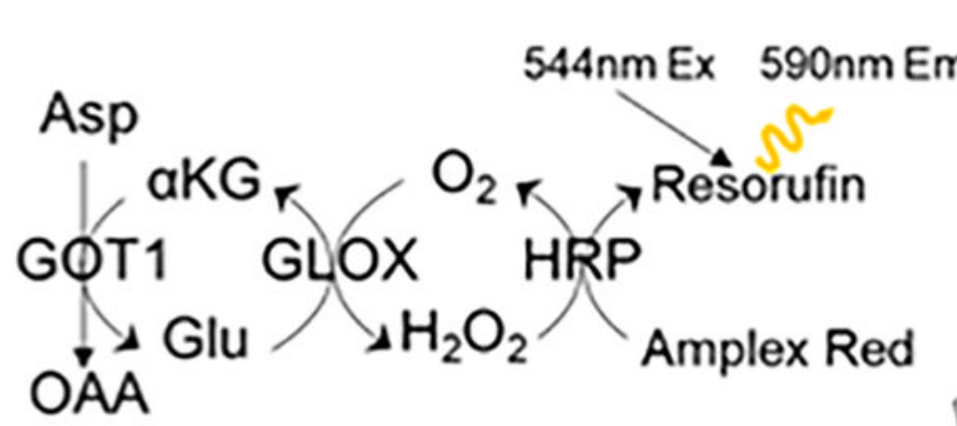

B Asp aKG
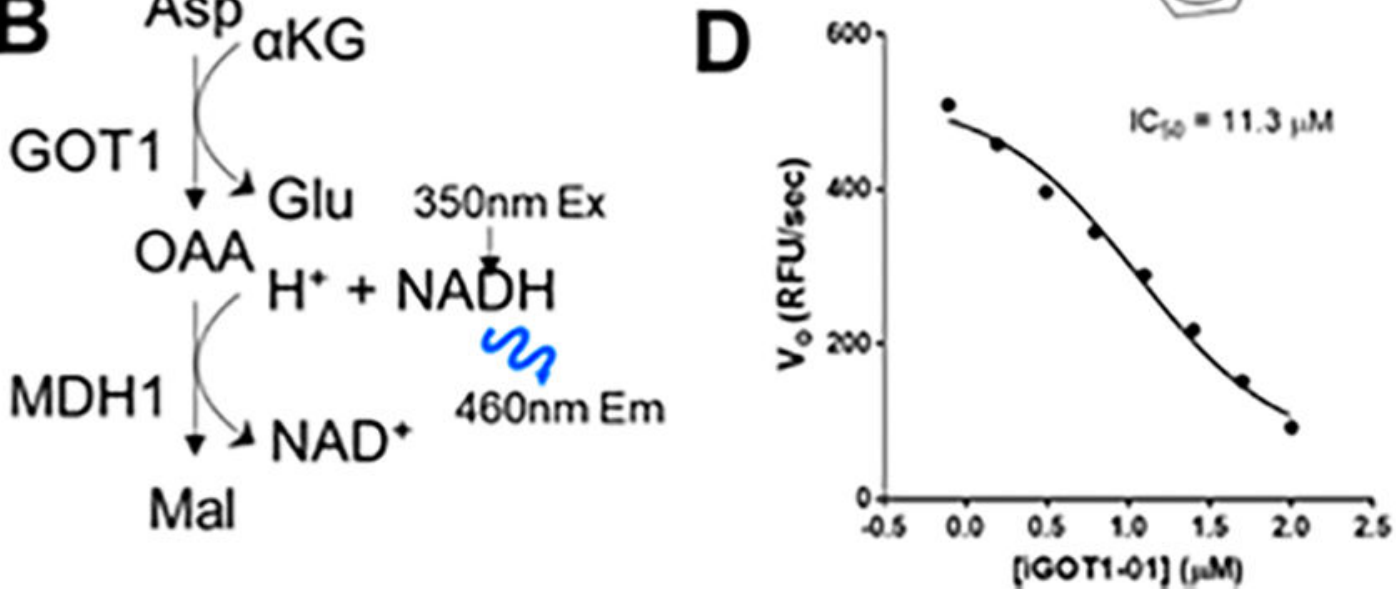

Figure 1.

High-throughput screening strategy and structure of the GOT1 inhibitor. (A) GLOX/HRPcoupled GOT1 assay. (B) Orthogonal MDH1-coupled GOT1 assay used to confirm GOT1 inhibition activity. (C) Chemical structure of GOT1 inhibitor hit iGOT1-01. (D)

Concentration-dependent inhibition of GOT1 activity by iGOT1-01, as determined using the GLOX/HRP-coupled assay $\left(\mathrm{IC}_{50} \sim 11.3 \mu \mathrm{M}\right)$. 

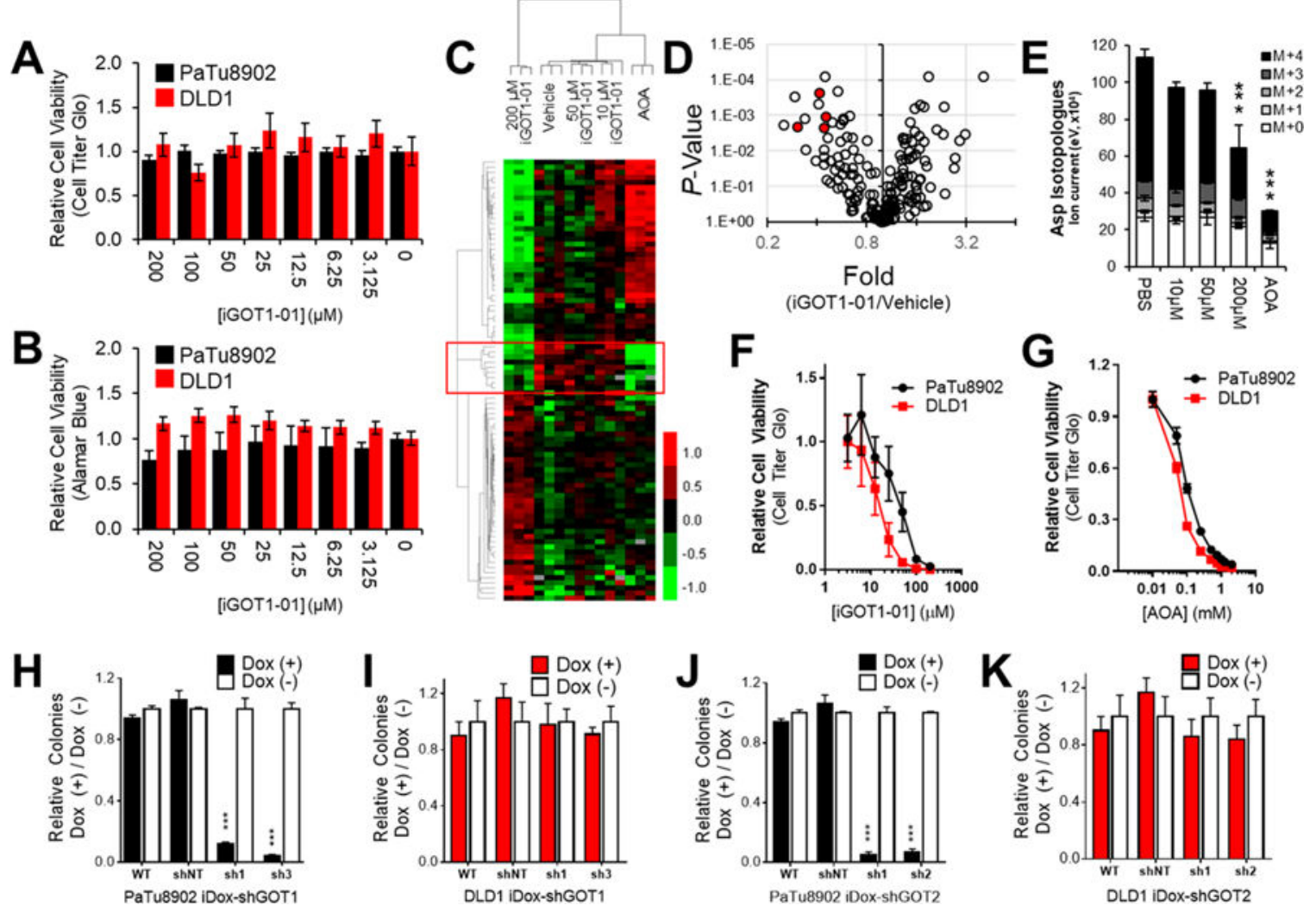

Figure 2.

iGOT1-01 activity in cell-based assays. (A and B) Impact of iGOT1-01 on cell viability using two independent readouts in pancreatic cancer cells (PaTu8902 in black) or colon cancer cells (DLD1 in red) after $3 \mathrm{~h}$. Relative cell viability as measured by (A) Cell Titer Glo and (B) Alamar Blue. (C) Heat map of altered metabolites $(P<0.1)$ as measured by mass spectrometry-based metabolomics for $\left[{ }^{13} \mathrm{C}\right]$ glutamine tracing in PaTu8902 cells after treatment with the compound for $3 \mathrm{~h}$. Data are arranged using two-dimensional unsupervised hierarchical clustering. Red represents metabolites that are more abundant, and green those that are less abundant. The levels of aspartate and glutathione metabolism are commonly decreased in iGOT1-01 $(200 \mu \mathrm{M})$ and positive control AOA-treated cells, as highlighted in the metabolite cluster in the red box. (D) Volcano plot of all of the metabolomics data for $200 \mu \mathrm{M}$ iGOT1-01-treated PaTu8902 cells relative to the vehicle. Data for Asp isotopologues are colored red. (E) iGOT1-01 exhibits a dose-dependent decrease in the level of aspartate isotopologues from ${ }^{13} \mathrm{C}$-labeled glutamine that is comparable to that seen upon treatment with AOA (positive control). $* * * P<0.001$. Dose-response curves for $(\mathrm{F})$ iGOT1-01 and (G) AOA in pancreatic cancer cells (PaTu8902 in black) and colon cancer cells (DLD1 in red). (H-K) GOT1 or GOT2 knockdown using two independent doxycycline (Dox)-inducible (iDox) shRNAs inhibits colony formation in the PaTu8902 pancreatic cancer cells (black) but not in the DLD1 colon cancer cells (red). WT, wild type; NT, nontargeting shRNA. $* * * P<0.001$. 


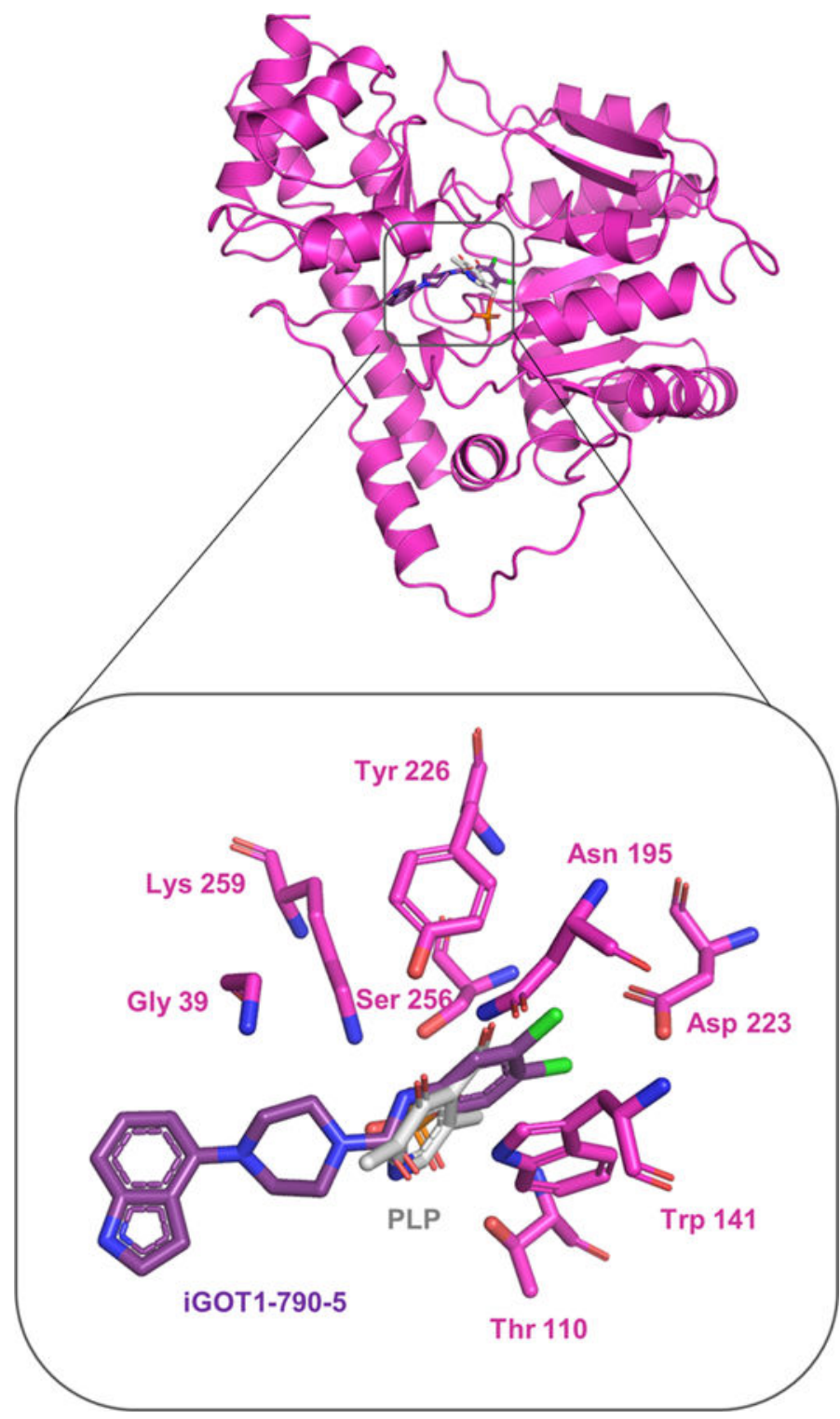

Figure 3.

In silico prediction of iGOT1-790-5 bound to WT-GOT1. iGOT1-790-5 (purple, shown as sticks) is predicted to bind within the PLP site (gray, shown as sticks). The presented pose showed the highest score $(-9.6 \mathrm{kcal} / \mathrm{mol})$. Thr110 and Ser 256 interact with PLP but are not predicted to interact with iGOT1-790-5. 


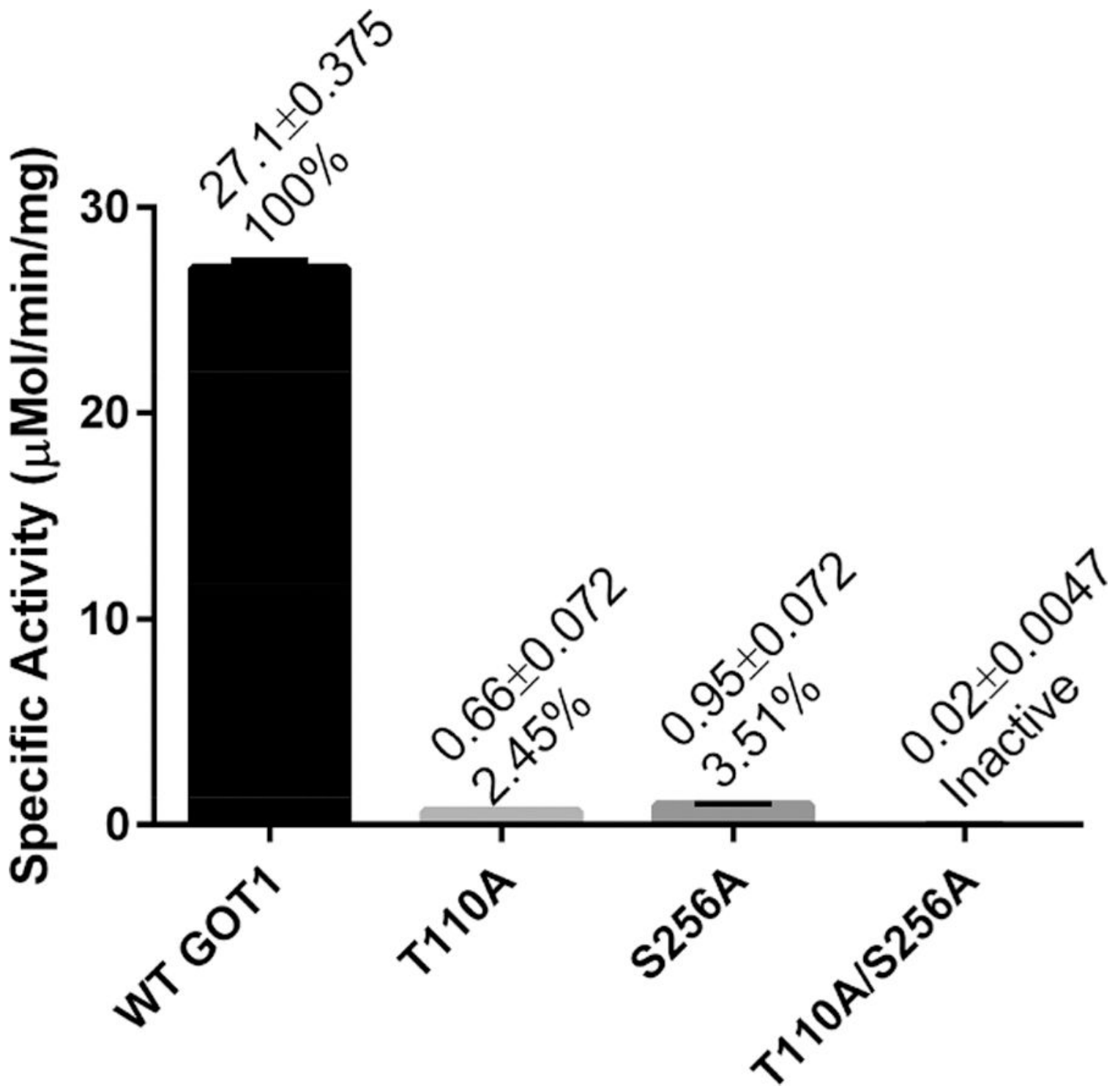

Figure 4.

WT-GOT1 and mutant GOT1 enzymatic activity. Bar graph comparing specific activities of WT vs mutant GOT1 samples based on the coupled Amplex Red assay. The GOT1 double mutant clearly shows no activity $\left(0.02 \mu \mathrm{mol} \mathrm{min}{ }^{-1} \mathrm{mg}^{-1} \mathrm{vs}\right.$ background detected at 0.04

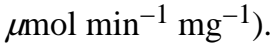



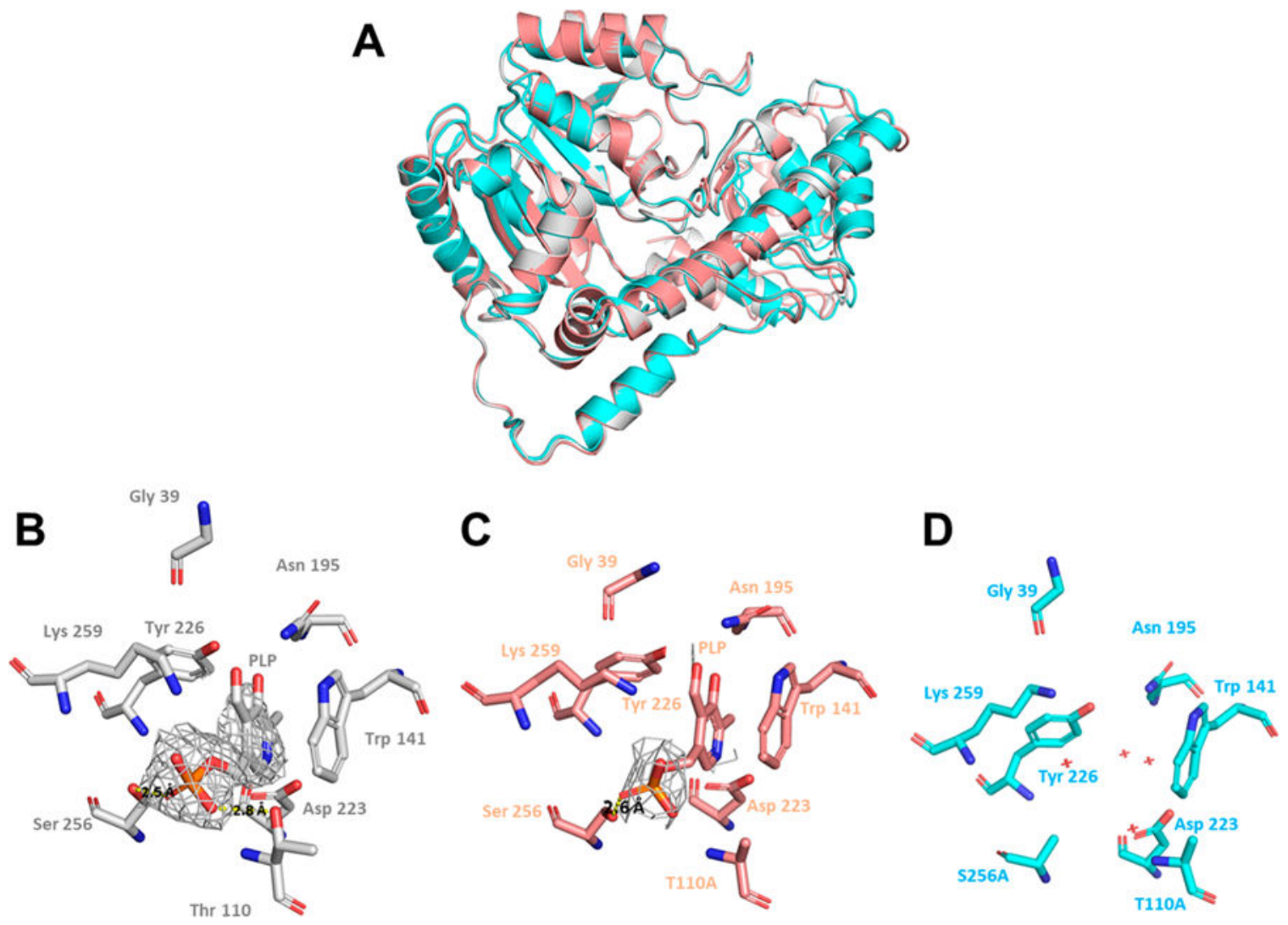

Figure 5.

WT-GOT1 and mutant GOT1 crystal structure overlay data. (A) Overlay of WT (gray), T110A (salmon), and T110A/S256A (cyan) GOT1 monomer crystal structures. (B) The $2 F_{\mathrm{O}}$ $-F_{\mathrm{c}}$ electron density map (gray) contoured at $1 \sigma$ around PLP in the WT-GOT1 structure. Residues around the PLP site are shown as sticks. The hydrogen bond distance is shown between Ser256 and PLP ( $2.8 \AA)$. (C) The $2 F_{\mathrm{o}}-F_{\mathrm{c}}$ electron density map (gray) contoured at $1 \sigma$ around PLP in the T110A mutant structure, refined with 70\% occupancy for PLP in the active site. Partial density is present for PLP compared to the WT structure. Residues around the PLP site are shown as sticks. The hydrogen bond distance is shown between Ser256 and PLP (2.6 ̊). (D) No density was observed for the PLP cofactor in the T110A/S256A mutant structure. Residues around the PLP site are shown as sticks. Water molecules (red pluses) were observed in the PLP site. 


\section{A}

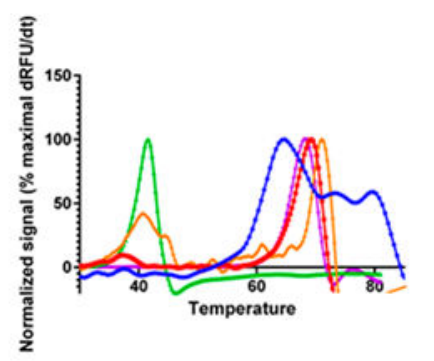

C

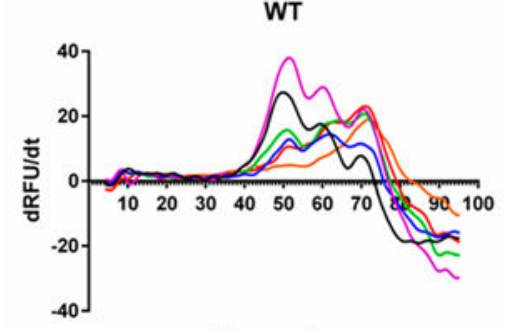

Temperature

E

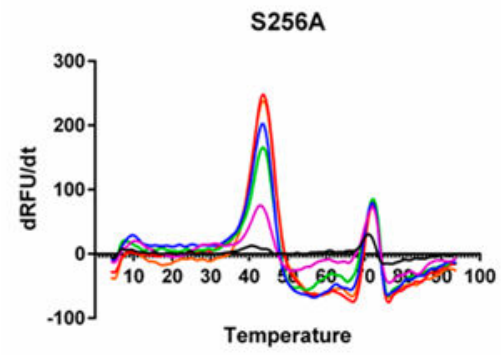

B

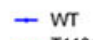

- T110A

- S256A

- T110A:S256A+1mM PLP
- Vehicle

- $0.69 \mu \mathrm{M}$

$-2.1 \mu \mathrm{M}$
$-6.2 \mu \mathrm{M}$

- $18.5 \mu \mathrm{M}$

- $55.5 \mu \mathrm{M}$

- Vehicle

- $1.95 \mu \mathrm{M}$

$-3.9 \mu \mathrm{M}$

- $7.8 \mu \mathrm{M}$

$-15.6 \mu \mathrm{M}$

- $31.2 \mu \mathrm{N}$
D

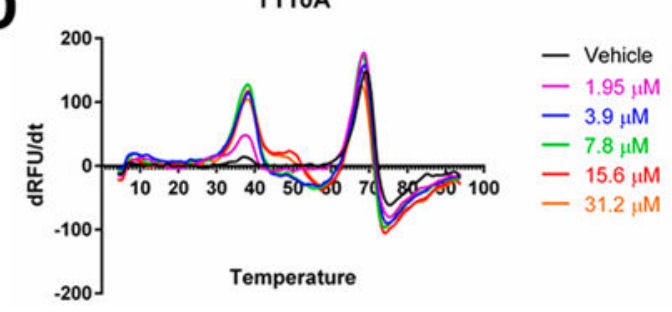

F

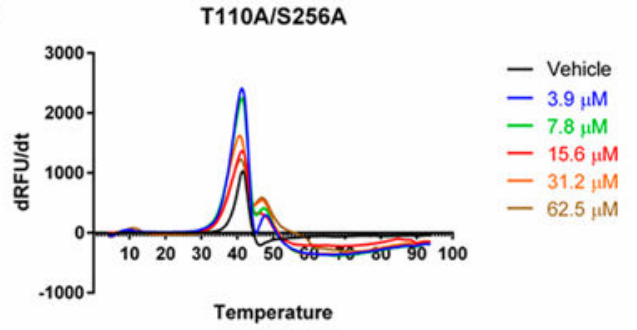

Figure 6.

Melting curves for WT-GOT1 and its mutants in the presence of iGOT1-074-8. (A) WT-

GOT1 and mutant protein melting profiles. (B) Melting profile for the T110A/S256A GOT1 double mutant across a PLP titration. Melting profiles for (C) WT, (D) T110A, (E) S256A, and (F) T110A/S256A GOT1 proteins across a range of iGOT1-074-8 concentrations. 
Table 1.

\section{Data Collection and Refinement Statistics}

\begin{tabular}{|c|c|c|c|}
\hline & WT & T110A & S256A/T110A \\
\hline \multicolumn{4}{|c|}{ Diffraction Statistics } \\
\hline wavelength $(\AA)$ & 0.9787 & 0.9787 & 0.9787 \\
\hline space group & $\mathrm{P} 212121$ & $\mathrm{C} 2$ & P6522 \\
\hline$a, b, c(\AA)$ & $91.03,96.86,97.87$ & $257.70,148.61,83.10$ & $84.08,84.08,210.12$ \\
\hline$a, \beta, \gamma(\mathrm{deg})$ & $90,90,90$ & $90,90,90$ & $90,90,120$ \\
\hline resolution $(\AA)$ & $50-2.10(2.15-2.10)^{a}$ & $50-3.00(3.08-3.00)^{a}$ & $50-1.7(1.74-1.70)^{a}$ \\
\hline no. of molecules in the asymmetric unit & 2 & 6 & 1 \\
\hline total no. of reflections & 48527 & 59429 & 46568 \\
\hline no. of unique reflections & 3512 & 4281 & 3272 \\
\hline completeness (\%) & $99.92(99.44)^{a}$ & $99.77(97.32)^{a}$ & $99.76(97.32)^{a}$ \\
\hline$I / \sigma(\mathrm{I})$ & $30.01(4.52)^{a}$ & $9.42(1.71)^{a}$ & $47.62(5.01)^{a}$ \\
\hline $\mathrm{R}_{\text {merge }} b$ & $0.07(0.32)^{a}$ & $0.09(0.61)^{a}$ & $0.08(0.51)^{a}$ \\
\hline \multicolumn{4}{|c|}{ Refinement Statistics } \\
\hline $\mathrm{R}_{\text {work }} / \mathrm{R}_{\text {free }}(\%)^{c}$ & $20.93 / 26.93$ & $18.86 / 21.21$ & $17.90 / 22.87$ \\
\hline no. of protein Atoms & 6,430 & 18,406 & 3,653 \\
\hline no. of waters & 102 & 10 & 237 \\
\hline no. of PLPs & 2 & 6 & - \\
\hline no. of PEGs & 2 & 3 & 2 \\
\hline no. of $\mathrm{PO}_{4}{ }^{3-}$ & - & - & 1 \\
\hline RMSD for bond lengths $\left(\AA^{2}\right)$ & 0.013 & 0.016 & 0.022 \\
\hline RMSD for bond angles (deg) & 1.57 & 1.93 & 2.16 \\
\hline PDB entries & 6DND & 6DNA & $6 \mathrm{DNB}$ \\
\hline
\end{tabular}

${ }^{a}$ Values in parentheses correspond to those for the highest-resolution shell.

${ }^{b} R_{\text {merge }}=\sum|I-\langle I\rangle| / \sum\langle I\rangle$, where $I$ is the integrated intensity of given reflection.

${ }^{c} R_{\text {work }}=\sum_{h k l} \| F_{\text {obs }}|-| F_{\text {calc }}\left|/ / \sum_{h k l}\right| F_{\text {obs }} \mid$. Five percent of the reflections were excluded from the $R$ free calculation. 